\title{
Simulasi Rising Kerbs Untuk Meminimalisasi Pelanggaran Lampu Lalu Lintas Menggunakan Teknik PWM
}

\author{
Afdal Al Hafiz', Yopi Hendro Syahputra ${ }^{2}$, Dudi Rahmadiansyah ${ }^{3}$ \\ ${ }^{1,2,3}$ Sistem Informasi, STMIK Triguna Dharma
}

\begin{tabular}{ll}
\hline \hline Article Info & ABSTRACT \\
\cline { 2 - 3 } Article history: & Transportasi merupakan salah satu faktor penting dalam kehidupan \\
Received Jan $12^{\text {th }}, 2022$ & masyarakat. Tingginya volume penggunaan kendaraan di usia produktif \\
Revised Jan $20^{\text {th }}, 2022$ & mengakibatkan meningkatnya jumlah pengguna jalan raya yang tidak \\
Accepted Feb $27^{\text {th }}, 2022$ & mematuhi peraturan lalu lintas. Akibatnya tingkat kecelakaan lalu lintas pun \\
& semakin meningkat. Rambu - rambu lalu lintas merupakan solusi untuk \\
& mengatasi masalah tersebut. dengan adanya rambu lalu lintas tingkat \\
Keyword: & pelanggaran peraturan lalu lintas dapat diminimalisir. Namun dari pengamatan \\
Mikrokontroler & yang telah dilakukan selama ini masih banyak pengguna kendaraan yang tidak \\
PWM & mematuhi peraturan yaitu dengan menerobos lampu lalu lintas. Pada penelitian \\
Rising Kerbs & ini akan dicoba mendesain suatu sistem simulasi rising kerbs untuk \\
Simulasi & mengantisipasi permasalahan tersebut dengan Teknik PWM berbasis \\
Transportasi & mikrokontroler. Rancangan yang dibangun berupa simpang empat dengan 4 \\
& buah traffic light, 4 buah servo, 4 buah sensor photodioda, dan 4 buat \\
& ATmega8. Hasil dari penelitian ini menunjukkan bahwa sistem rising kerbs \\
dapat berjalan sesuai perputaran traffic light dan rising kerbs bekerja juga \\
berdasarkan sensor photodiode ketika mndeteksi objek macet pada saat lampu \\
merah.
\end{tabular}

\author{
Corresponding Author: *First Author \\ Nama : Afdal Al Hafiz \\ Program Studi : Sistem Komputer \\ STMIK Triguna Dharma \\ Email: afdal.alhafiz@trigunadharma.ac.id
}

\section{PENDAHULUAN}

Transportasi memiliki peran yang sangat strategis dalam mendukung fungsi suatu wilyah. Untuk itu, transportasi sebagai media pergerakan barang dan jasa harus mampu mencerminkan tingkat efesien dan efektifitas wilayah dalam hal mobilitas dan aksesbilitas baik secara internal maupun secara eksternal [1]. Kecelakaan lalu lintas adalah kejadian dimana sebuah kendaraan bermotor bertabrakan dengan benda lain dan menyebabkan kerusakan. Kadang kecelakaan ini dapat mengkibatkan luka-luka atau kematian manusia atau binatang [2]. Tingginya volume penggunaan kendaraan diusia produktif juga mengakibatkan meningkatnya jumlah kecelakaan lalu lintas di jalan raya. Selain karena volume kendaraan hal ini juga sering disebabkan karena kesalahan manusia (Human Error). Kapolri menambahkan, bahwa sebagian besar korban kecelakaan lalu lintas disebabkan oleh banyak faktor. Dan yang yang menjadi sorotan adalah tidak disiplinnya para pengendara kendaraan bermotor. Itu semua akibat dari kurangnya kesadaran pengguna kendaraan akan faktor keamanan berkendaraan serta kurangnya sanksi dan sistem yang efektif untuk menekan kesalahan manusia (Human Error).

Salah satu permasalahan yang selalu dihadapi beberapa kota besar di Indonesia adalah masalah lalu lintas. Hal ini terbukti dari adanya indikasi angka kecelakaan lalu lintas yang selalu meningkat. Keadaan ini merupakan salah satu perwujudan dan perkembangan teknologi modern [3]. Rambu - rambu lalu lintas merupakan hal yang terpenting bagi ketertiban dan keselamatan pengguna kendaraan. Ditambah lagi dengan kebutuhan yang tinggi akan kendaraan, baik kendaraan umum maupun kendaraan pribadi, khususnya pada kendaraan darat. Hal ini mengakibatkan peningkatan jumlah pengguna kendaraan yang membutuhkan alat transportasi. 
Rancangan menggunakan mikrokontroler ATMega 8 sebagai pengendali, sensor gerak (PIR) sebagai pendeteksi gerak manusia, sensor gas dan api sebagai pendeteksi kebocoran gas dan kebakaran. Kontroler ATMega 8 digunakan untuk mengendalikan sistem secara keseluruhan [4].

Alat pengiris bawang yang menggunakan teknik Pulse Witdh Modulation (PWM) ini dapat memudahkan manusia untuk mengiris bawang dengan lebih mudah dan cepat, dan alat ini lebih praktis dan tidak berbahaya dan tidak membuat mata menjadi perih. Dan alat ini dapat digunakan untuk skala besar [5].

Salah satu ide untuk mengurangi angka kecelakaan lalu lintas akibat kesalahan manusia (Human Error) adalah dengan membuat suatu sistem trotoar otomatis / rising kerbs pada persimpangan jalan raya dengan teknik PWM berbasis mikrokontroler. Dimana sistem rising kerbs ini akan membuat pengendara tidak dapat menerobos lampu merah dan juga memberikan efek jera sehingga dapat menekan pelanggaran rambu lalu lintas. Sistem ini bekerja dengan menutup dan membuka di sekitar garis batas berhenti kendaraan. Sistem yang dirancang dilengkapi sensor photodioda sebagai pendeteksi kendaraan yang terjebak macet di garis batas berhenti kendaraan disaat lampu merah menyala.

\section{METODE PENELITIAN}

Metode penelitian merupakan aturan yang harus dilakukan dalam suatu penelitian agar hasil yang diperoleh lebih maksimal. Salah satu yang termasuk di dalam metodologi penelitian adalah kerangka kerja baik kerangka kerja sistem yang akan dihasilkan maupun prosedur aritmatik yang terdapat di dalam sistem. Tujuan lain dari metodologi penelitian yaitu membuat sistem menjadi lebih terstruktur. Berikut gambar 1 kerangka kerja penelitian di bawah ini.

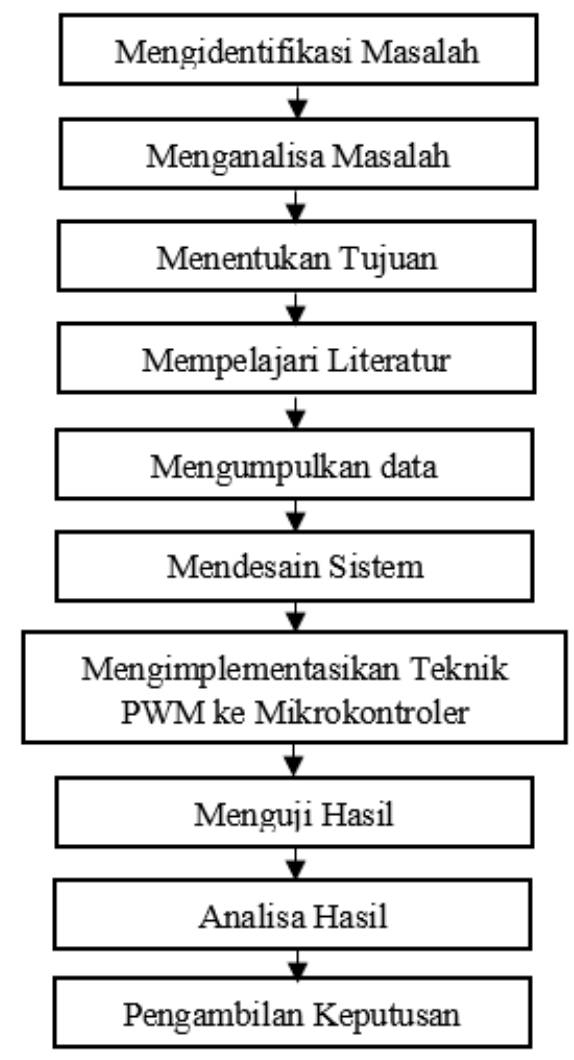

Gambar 1. Kerangka Kerja

Berdasarkan kerangka kerja pada gambar 1 maka dapat dijabarkan langkah langkah kerja penelitian sebagai berikut :

1. Mengidentifikasi masalah

Masalah yang diidentifikasi dalam penelitian ini adalah kesulitan dalam mengimplementasikan metode sistem dan matematis ke dalam hardware yakni mikrokontroler.

2. Menganalisa masalah 
Analisa yang akan dilakukan dalam penelitian ini adalah algoritma dalam menentukan naik dan turunnya rising kerbs pada simpang 4 jalan raya.

3. Menentukan Tujuan

Adapun target yang akan dituju dalam penelitian ini adalah mengimplementasikan sebuah teknik ke dalam Atmega8 yang dapat diterapkan ke dalam simulasi sistem rising kerbs.

4. Mempelajari Literatur

Literatur yang digunakan bersumber dari jurnal-jurnal ilmiah Teknik PWM, modul pembelajaran, buku tentang sensor dan transduser, dan mikrokontroler Atmega8.

5. Mengumpulkan data

Untuk memperoleh data - data yang dibutuhkan dalam proses perancangan sistem ini, maka digunakan metode - metode sebagai berikut:

a. Studi kepustakaan (Library Research)

b. Pengamatan (Observation)

c. Dokumentasi

6. Mendesain Sistem

Pada tahap ini data yang dikumpulkan akan diolah dan diimplementasikan ke dalam sistem hardware dengan penerapan teknik yang telah ditentukan. Desain sistem yang dimaksud berupa perencanaan serta perancangan simulasi simpang lalu lintas dam bentuk prototipe.

7. Implementasi Teknik PWM

Dalam proses membangun sistem, penggunaan Teknik PWM diimplementasikan bertujuan untuk mengatur duty cycle yang tepat sehingga rising kerbs bekerja optimal

8. Pengujian Hasil

Pada bagian ini hasil dari sistem rising kerbs yang telah dirancang akan diuji coba dan disimulasikan dengan permasalahan lalu lintas pada sistem nyata. Hal ini dilakukan untuk melihat hasil kinerja alat apakah sesuai dengan yang diharapkan.

9. Analisa Hasil

Hasil yang diperoleh dari ujicoba sistem kemudian akan dianalisa. Keakuratan hasil pada sistem yang dirancang harus bisa memecah permasalahan pada sistem nyata yang berjalan

10. Pengambilan Keputusan

Setelah keseluruhan hasil uji coba dan analisa diperoleh tahap terakhir adalah pengambilan keputusan akan kelayakan sistem yang dirancang.

\section{ANALISA DAN HASIL}

3.1. Algoritma Sistem

Algoritma sistem dapat dilihat pada gambar 2 berikut ini.

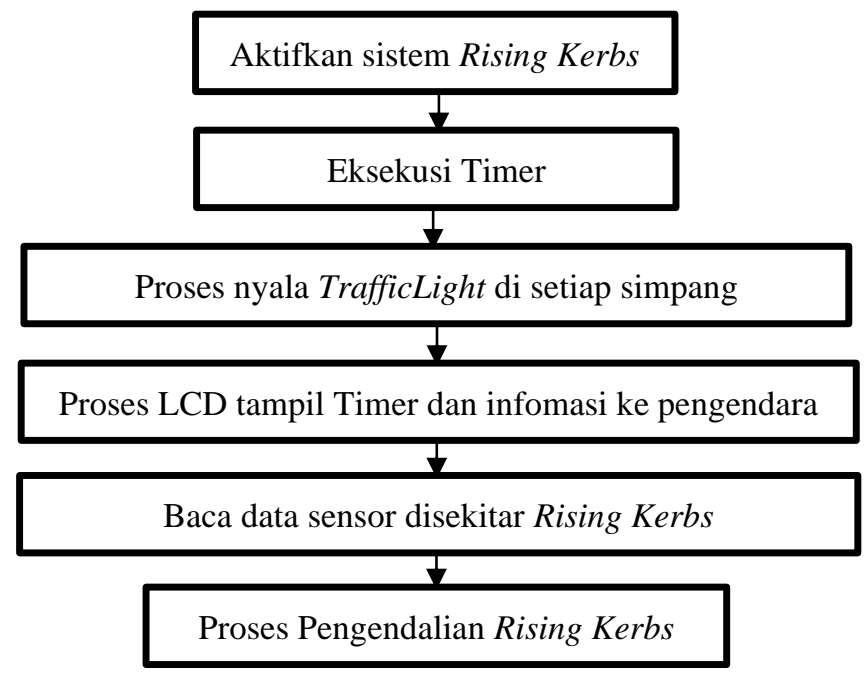

Gambar 2. Algoritma Sistem

Aliran proses algoritma dimulai dari pengaktifan sistem rising kerbs, lalu sistem akan mengeksekusi timer untuk menyalakan traffic light secara bergantian di setiap simpang, selanjutya lcd akan menampilkan data timer 
dan informasi ke pengendara, lalu data kendaraan yang terjebak macat di atas rising kerbs akan dideteksi sensor.

\subsection{Blog Diagram}

Blok diagram dapat dilihat pada gambar 3 berikut ini.

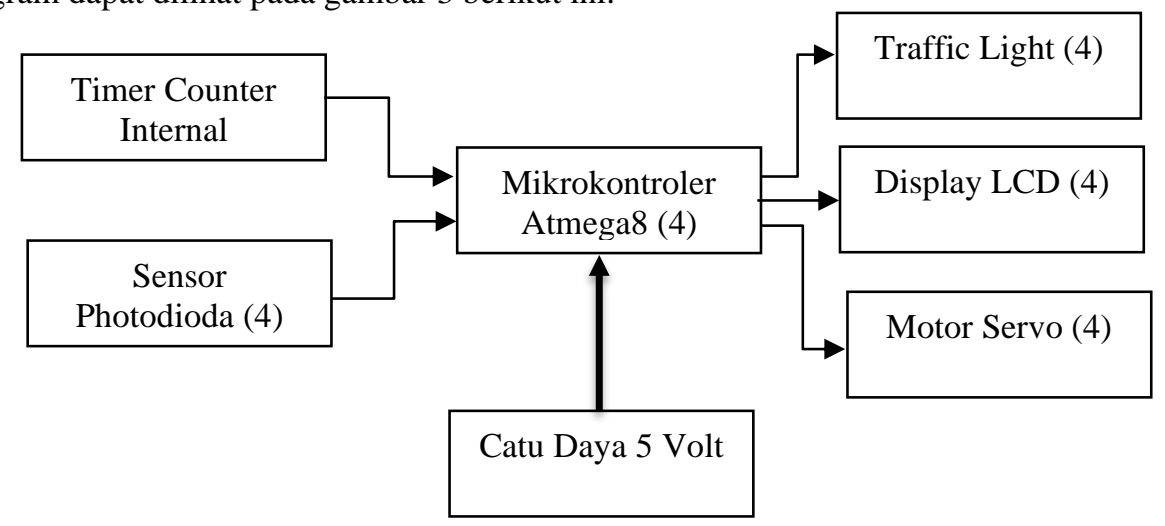

Gambar 3. Blog Diagram

Dari blog diagram sistem rising kerbs pada gambar 3 selanjutnya dapat diuraikan fungsi dari masing masing blok sebagai berikut.

1. Timer Counter internal

Bagian timer counter ini difungsikan untuk membangkitkan detak waktu delay pergantian traffic Light di setiap simpang.

2. Sensor Photodioda

Sensor dirancang sebanyak 4 buah untuk menangkap objek kendaraan yang terjebak di atas rising kerbs pada saat lampu merah menyala.

3. Mikrokontroler Atmega8

Mikrokontroler Atmega8 dirancang sebagai pusat kendali pengatur alur dari input menuju output dan disini juga diterakan teknik PWM.

4. Catu daya 5 Volt

Sebagai sumber daya tegangan DC untuk berjalannya keseluruhan sistem.

5. Traffic Light

Traffic light dirancang menggunakan LED merah, kuning, hijau di setiap simpang

6. Display LCD

LCD yang digunakan sebanyak 4 buah dengan tipe $16 \times 2$ untuk menampilkan data timer dan informasi.

7. Motor Servo

Servo difungsikan untuk pengendali Rising Kerbs naik dan turun , servo yang digunakan tipe $180^{\circ}$

\subsection{Rangkaian Keseluruhan}

Rangkaian keseluruhan merupakan gabungan dari keseluruhan komponen yang dibutuhkan agar sistem dapat bekerja optimal. Pada gambar 4 berikut terlihat kombinasi keseluruhan seperti 4 buah Atmega8, 4 buah LCD 16 x 2, 4 buah sensor Photodioda, 4 buah Motor Servo, 4 buah Traffic Light, dan sebuah 


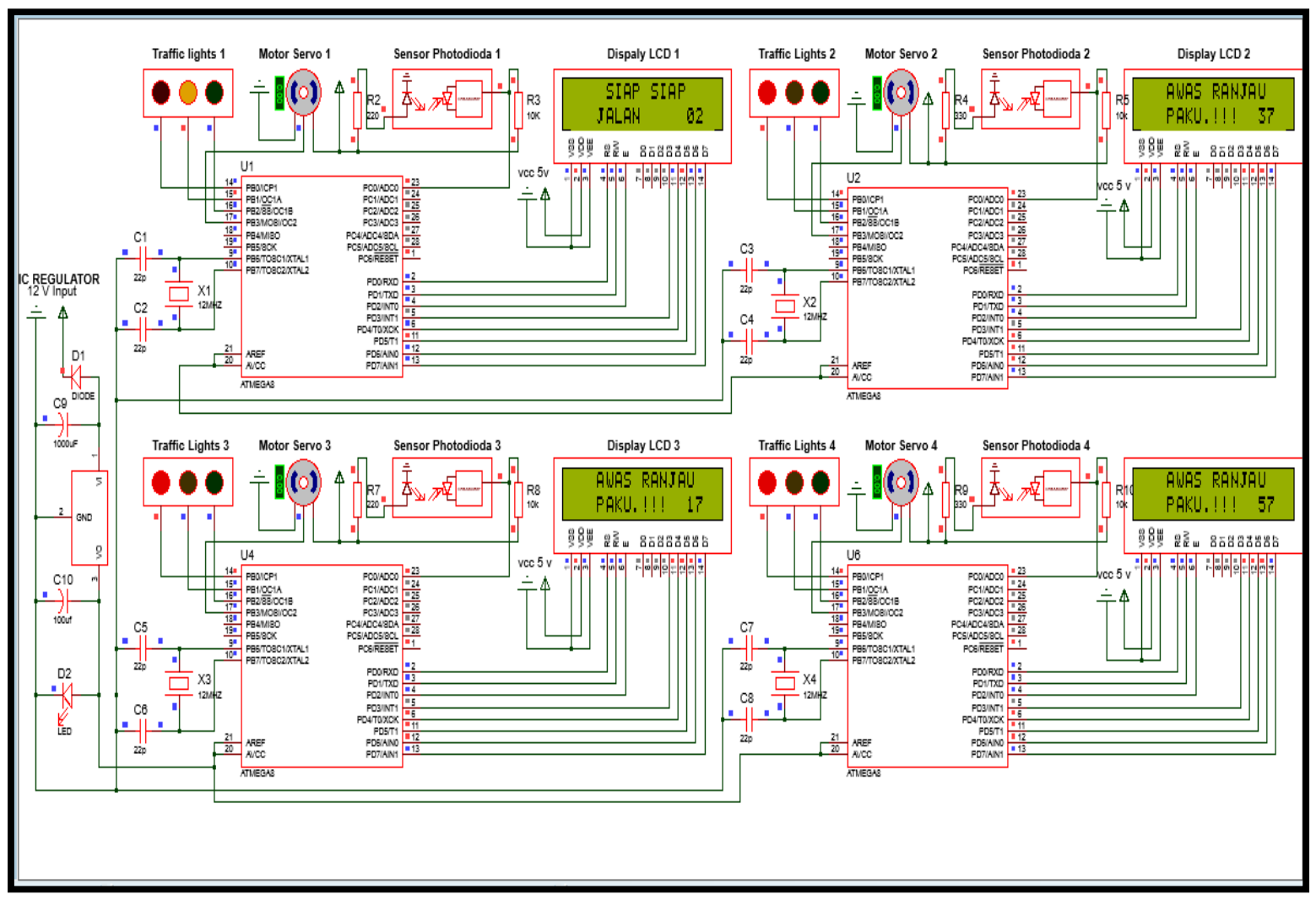

Gambar 4. Rangkaian Keseluruhan

\subsection{Implementasi Teknik PWM pada Sistem Rising Kerbs}

Implementasi teknik PWM diterapkan pada pergerakan motor Servo sebanyak 3 step pergerakan saat naik dan turun yaitu dengan memberi pulsa HIGH LOW dengan delay milisecond dalam waktu tertentu sehingga mempengaruhi tegangan yang mengalir di kabel input servo, pada sistem ini tegangan di kabel input motor servo adalah dari 0 sampai 5 Volt yang mempengaruhi pergerakkan derajat. resolusi pulse width modulation dipakai sebesar 8 bit (256) yang berarti setiap nilai direpresentasikan dengan angka 0 sampai 255. Berikut nilai pwm yang akan diimplementassikan pada tiap step motor servo.

1. Duty Cycle $10 \%$ (Pergerakan servo step 1)

$\mathrm{PWM}=$ Duty Cycle $\mathrm{X}$ Resolusi PWM

$$
\begin{aligned}
& =10 \% \times 255 \\
& =25,5
\end{aligned}
$$

$\mathrm{V}$ out $=$ Duty Cycle $\mathrm{x} \mathrm{V}$ in

$$
\begin{aligned}
& =10 \% \times 5 \\
& =0,5 \text { Volt }
\end{aligned}
$$

Pada saat duty cycle $10 \%$ dan resolusi yang digunakan adalah 8 bit maka dihasilkan nilai pwm sebesar 25,5 , sedangkan tegangan yang mengalir ke kabel input servo adalah 0,5 Volt sehingga menyebabkan servo (Rising kerbs) berada di kondisi naik step 1

2. Duty Cycle $20 \%$ (Pergerakan servo step 2)

$\mathrm{PWM}=$ Duty Cycle $\mathrm{X}$ Resolusi PWM

$$
\begin{aligned}
& =20 \% \times 255 \\
& =51
\end{aligned}
$$


$\mathrm{V}$ out $=$ Duty Cycle $\mathrm{x} \mathrm{V}$ in

$$
=20 \% \times 5
$$$$
=1 \text { Volt }
$$

Pada saat duty cycle $20 \%$ dan resolusi yang digunakan adalah 8 bit maka dihasilkan nilai pwm sebesar 51 , sedangkan tegangan yang mengalir ke kabel input servo adalah 1 Volt sehingga menyebabkan servo (Rising kerbs) berada di kondisi naik step 2

3. Duty Cycle $30 \%$ (Pergerakan servo step 3)

$\mathrm{PWM}=$ Duty Cycle $\mathrm{X}$ Resolusi PWM

$$
\begin{aligned}
& =30 \% \times 255 \\
& =76,5
\end{aligned}
$$

$\mathrm{V}$ out $=$ Duty Cycle $\mathrm{x} \mathrm{V}$ in

$$
=30 \% \times 5
$$$$
=1,5 \text { Volt }
$$

Pada saat duty cycle $20 \%$ dan resolusi yang digunakan adalah 8 bit maka dihasilkan nilai pwm sebesar 76,5 sedangkan tegangan yang mengalir ke kabel input servo adalah 1,5 Volt sehingga menyebabkan servo (Rising kerbs) berada di kondisi naik step 3

\subsection{Hasil dan Diskusi}

Hasil dari perancangan sistem dibangun menggunakan simulasi simpang lalu lintas dimana seluruh alat dan bahan yang dibutuhkan dirangkai sesuai prosedur. Pengujian untuk sistem yang dibuat dilakukan dengan mensimulasikan permasalahan yang terjadi di kehidupan nyata ke dalam mimiatur alat, yaitu saat pengendara mencoba menerobos disaat lampu merah menyala, pengujian dilakukan di setiap keempat simpang. Berikut dapat dilihat pada gambar 5 dibawah ini.
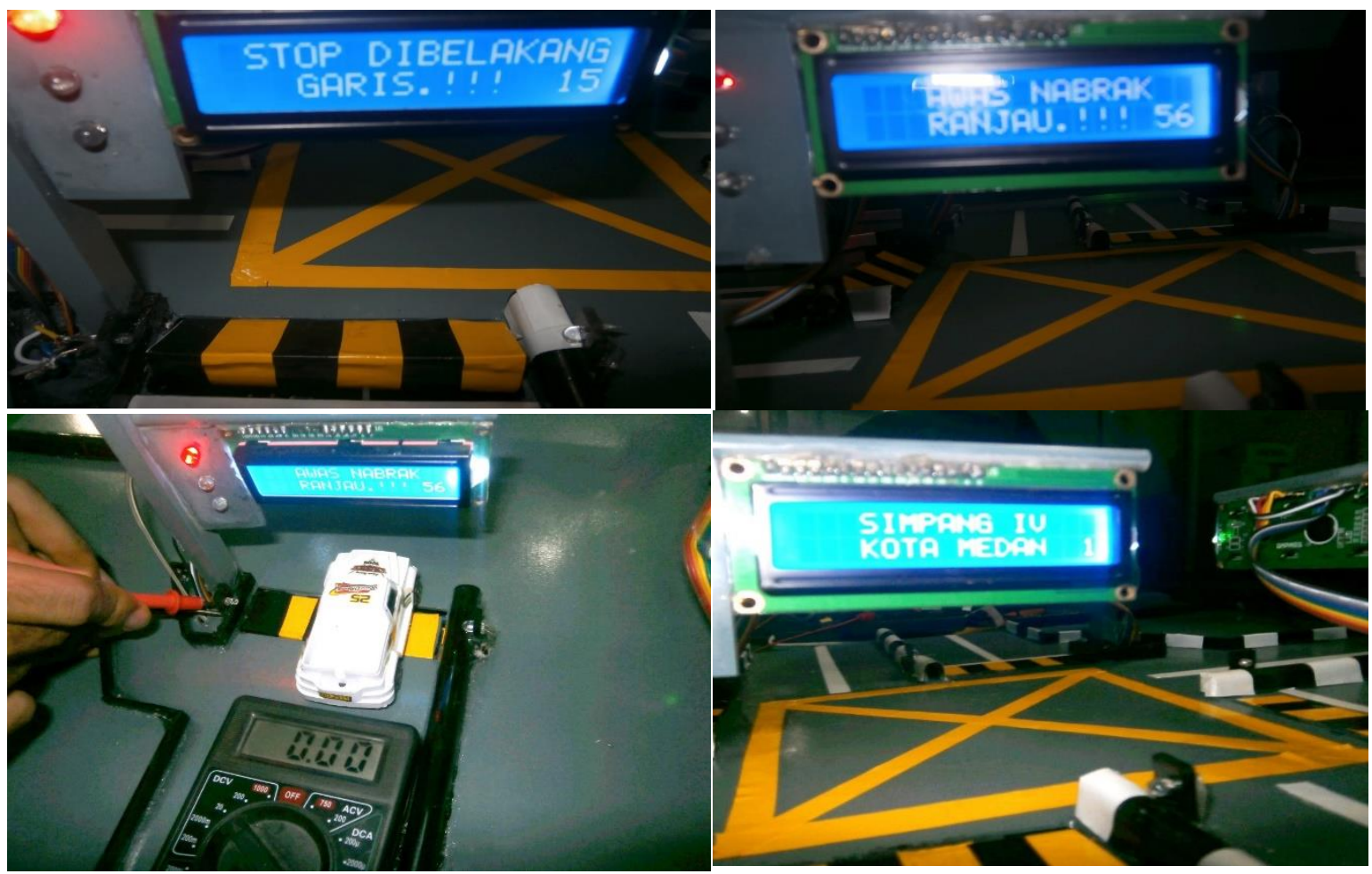

Gambar 5. Pengujian Sistem 


\section{KESIMPULAN}

Dari hasil pengujian simulasi rising kerbs atau trotoar otomatis dapat diambil beberapa kesimpulan, antara lain sebagai berikut :

1. Berdasarkan hasil Rancangan sistem rising kerbs dapat bekerja secara otomatis dengan baik, dapat naik dan turun dengan sendirinya berdasarkan lampu traffic light dan saat ada kendaraan yang terjebak.

2. Berdasarkan pengujian timer dan tampilan 4 buah LCD didapat bahwasannya waktu pergantian dan informasi ke pengendara berjalan sesuai prosedur yang diharapkan

3. Berdasarkan pengujian sensor photodioda didapatkan hasil setiap lampu merah menyala maka disaat itulah sensor akan aktif dan membaca objek di setiap simpang.

4. Berdasarka analisa Ujicoba sistem keseluruhan berjalan secara kontinu atau berkelanjutan sehingga jalannya setiap komponen yang terpasang tidak saling bertabrakan.

\section{REFERENSI}

[1] Silondae S. et al(2016) "Keterkaitan Jalur Transportasi Dan Interaksi Ekonomi Kabupaten Konawe Utara Dengan Kabupaten/Kota Sekitarnya" e-ISSN 2502-5171.

[2] Dwi Saputra A.(2017) "Studi Tingkat Kecelakaan Lalu Lintas Jalan di Indonesia Berdasarkan Data KNKT (Komite Nasional Keselamatan Transportasi) Dari Tahun 2007-2016.

[3] Hidayah A.(2017)"Ensiklopedia Traffic Signs; Solusi Cerdas Memperkenalkan Road Safety Culture Pada Anak Sekolah" ISSN 2355-3766.

[4] Lubis Z and Aryza S(2017) “Analisa Perancangan Penggunakan Mikrokontroler ATMega 8 Sebagai Pengendali dan Sensor Gerak untuk Pendeteksi Gerak Berbasis SMS” ISSN : 2598 - 1099 (Online).

[5] Prayudha J. et al(2020) "Rancang Bangun Alat Pengiris Bawang Dengan Teknik Pulse Witdh Modulation (PWM) Berbasis Mikrokontroler" P-ISSN : 1978-6603. 